\title{
ESTIMATIVA DA ELASTICIDADE-RENDA DO CONSUMO DE CAFÉ NA REGIÃO SUDESTE DO BRASIL ${ }^{1}$
}

\author{
Venússia Eliane Santos ${ }^{2}$ \\ Marco Túlio M. Gomes ${ }^{3}$ \\ Marília Fernandes Maciel Gomes ${ }^{4}$
}

Resumo - Analisaram-se, neste trabalho, as mudanças ocorridas na quantidade consumida de café torrado e moído, em resposta à alteração na renda dos consumidores na região Sudeste do Brasil, especificamente nos estados de Minas Gerais, São Paulo e Rio de Janeiro, e no total das áreas da POF (Brasil). Para isso, estimaram-se elasticidadesrenda do consumo desse tipo de café pelo modelo econométrico, que consiste em ajustar uma poligonal com três segmentos, para mostrar como o consumo físico per capita desse tipo de café altera em decorrência da variação no recebimento mensal familiar per capita. Os dados foram provenientes da Pesquisa de Orçamento Familiar de 2002/2003, publicada pelo IBGE. Os resultados demonstraram elasticidade-renda maior que zero e menor que um para café torrado e moído, o que indica que este produto é considerado um bem normal nas regiões analisadas, ou seja, uma variação na renda do consumidor acarretará uma variação menos que proporcional no consumo de café.

Palavras chaves: elasticidade-renda, consumo de café, região Sudeste.

\section{Introdução}

O café foi responsável por um dos ciclos mais importantes da história econômica brasileira. Em determinada época, o país orgulhava-se de ser essencialmente agrícola, e o principal produto de exportação era o café, que constituía a principal fonte de divisas.

\footnotetext{
Recebido em 30/06/2005. Aceito em 05/09/2005.

2 Mestranda em Economia Aplicada do Departamento de Economia Rural. Universidade Federal de Viçosa. Viçosa-MG. E-mail venussia@qmail.com.

3 Mestrando em Engenharia Florestal da Universidade Federal de Viçosa - Viçosa-MG, e-mail mtulio@vicosa.ufv.br.

4 Professora do Departamento de Economia Rural, UFV. CEP 36570-000 - Viçosa-MG. E-mail: mfmgomes@ufv.br.
} 
Com o passar do tempo, no entanto, ocorreram mudanças na pauta de exportações brasileiras, mas o café continuou a ter grande peso e importância, permanecendo entre os produtos agrícolas exportáveis.

$\mathrm{Na}$ década de 70, as políticas governamentais que mantiveram o preço do café elevado resultaram na ineficiência da produção e na baixa qualidade do produto produzido no país. Com a queda dos preços no início da década de 80 , houve necessidade de melhoria na qualidade do café e de busca da eficiência na produção, para recuperar a parcela perdida no mercado internacional.

Quanto à década de 80, esta não foi favorável ao consumo de café, em razão da recessão econômica enfrentada pelo país, aliada à baixa qualidade do produto e à falta de uma política econômica para o mercado interno de café. A recessão pela qual passou o país nesse período, em face da adoção do Plano Cruzado II, da elevação da taxa de juros e do impacto inflacionário, fez com que diminuísse o poder de compra da população, principalmente das classes mais baixas, o que inibiu o consumo de produtos de maior industrialização, tais como o café moído e torrado e o café solúvel (Costa, 2003).

Observa-se, também, a crise do produtor brasileiro, conseqüência direta da política de valorização da moeda em 1986 (referente à adoção do Plano Collor) e do término das políticas subsidiárias do governo para o café.

Com a adoção do Plano Real em 1994, houve controle da inflação mediante a estabilização econômica do país e valorização da moeda e observou-se crescimento do poder de compra da população, principalmente das classes mais baixas, o que possibilitou o consumo de outros bens e alimentos e a ampliação da demanda de café.

Em 1996, o mercado de café já se diversificara, e aos consumidores eram ofertados produtos de melhor qualidade, o que fez com que esse produto deixasse de ser uma commodity. Um fato importante relacionado com a diversificação da produção de café é a inserção da mulher no 
mercado de trabalho, o que fez com que aumentasse a demanda de produtos diversificados, de preparação mais fácil, com vistas em reduzir o tempo gasto no preparo de alimentos.

De modo geral, paralelo às mudanças no mercado cafeeiro, a economia brasileira passou por momentos conturbados ao longo das últimas décadas, em razão de um processo inflacionário crônico que corroeu o poder de compra dos consumidores. Nesse sentido, torna-se importante verificar a sensibilidade da variação do consumo de café às mudanças na renda dos consumidores em 2002/2003, em face dos problemas vividos pelo mercado cafeeiro e das políticas econômicas implementadas pelo governo.

Diante do exposto, objetivou-se, neste trabalho, avaliar as mudanças na quantidade consumida de café torrado e moído em resposta à alteração na renda dos consumidores na região Sudeste do Brasil, especificamente nos estados de Minas Gerais, Rio de Janeiro, São Paulo, Espírito Santo e no total da população. A justificativa da escolha de tais regiões é que nessas áreas há expressivo consumo de café e nelas concentra grande número de trabalhadores com vários estratos de renda.

Detidamente, o que se pretende analisar é como o consumo de café, nas cinco áreas estudadas, comportou-se diante da mudança de classe de renda, no ano de 2002/2003.

\subsection{Análise do mercado de café}

A cadeia de café movimenta mundialmente, por ano, cerca de 35 bilhões de dólares. Distribuída em todos os continentes, essa cultura tem seus dois maiores produtores situados na América do Sul - Brasil e Colômbia.

A história da cafeicultura brasileira é caracterizada por uma série de flutuações nos preços e no volume de produção, conseqüência de excessos de produção, geada, pragas, intervenções governamentais e acordos internacionais. 
Na safra 2001/2002, a produção mundial de café ficou em torno de 117,739 milhões de sacas de café em grão. O Brasil, o maior produtor mundial, apresentou uma produção anual de 27,490 milhões de sacas, que representou cerca de $23,35 \%$ da produção mundial. No período, foi também grande consumidor, visto que consumiu quase metade do que produziu (Gomes et al., 2002).

O mercado de café tem experimentado, desde o início da década de 90, liberdade de mercado, mas a competitividade brasileira, nos anos 90, pouco se alterou e em alguns dos segmentos, como no caso do café solúvel, deteriorou-se. Pode-se imputar esse desempenho a circunstâncias bastante adversas. Em primeiro lugar, à queda vertiginosa dos preços internacionais no início dos anos 90, a qual reduziu drasticamente a lucratividade do segmento produtor (Hemerly, 2000).

Em segundo, em 1994, quando os preços já iniciavam uma recuperação, a cafeicultura sofreu graves problemas climáticos, e a safra em 1995 ficou reduzida a 16,8 milhões de sacas (Anuário Estatístico do Café, 2002). A inexistência de uma política de financiamento à comercialização não permitiu que os produtores se beneficiassem dos preços elevados em face da escassez do produto. Até a safra 97/98, a produção brasileira ficou aquém da soma das demandas doméstica e externa, o que contribuiu para preços internacionais bastante atraentes.

O incentivo dos preços acabou revertendo a tendência de redução nas lavouras cafeeiras e, na safra 1997/98, observou-se maior produção que a de 1993/94. O movimento de expansão da produção, a partir de meados da década de 90, deu-se com aumento da produtividade, em decorrência da maior participação do cultivo adensado, que resultou também em índices de utilização de tratos culturais superiores aos observados no período anterior a 1993 (FAEMG, 1996).

No que se refere ao consumo, o Brasil, historicamente, tem sido um dos maiores consumidores de café do mundo. No mercado interno, o consumo foi de 4,72, em 1965; reduziu-se para 2,27 Kg/habitante, em 1985; aumentou para $3,81 \mathrm{Kg} /$ habitante, em 2000; e, em 2004, chegou a 4,01 $\mathrm{Kg} /$ habitante (ABIC, 2005). 
No final da década de 80 , houve pequena recuperação do consumo, em razão de aumento na produção (tanto nacional quanto internacional) e da queda nos preços (conseqüência do aumento da oferta) (Figura 1). Este quadro tendeu a se inverter também pelo efeito das medidas de marketing adotadas pela ABIC e da criação do selo de pureza em 1989. Mesmo assim, em meados da década de 90, o consumo brasileiro de café ainda Estava em torno de 3,11 Kg/habitante.

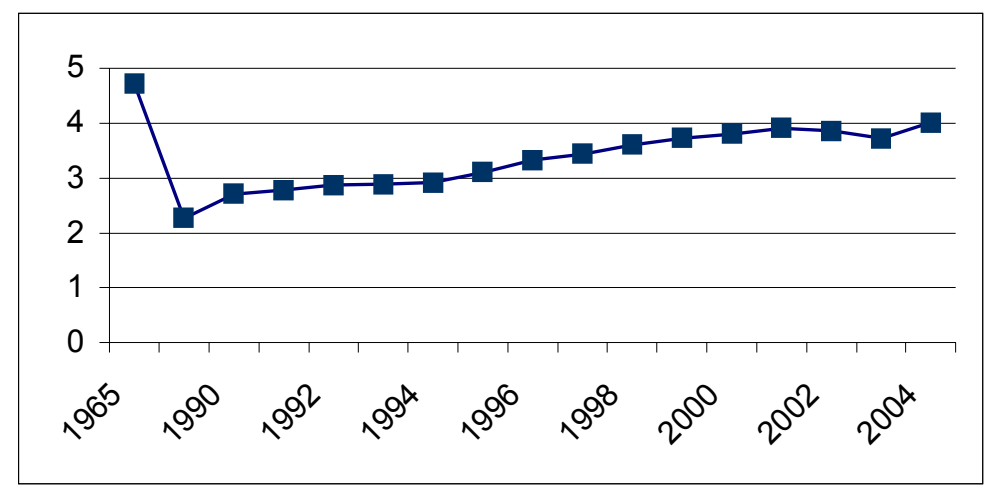

Fonte: ABIC, 2005.

Figura 1 - Evolução do consumo per capita de café torrado, no período de 1965 a 2004.

A tendência crescente do consumo per capita de café deveu-se, ao menos em parte, à melhoria na imagem do produto, que era considerado de má qualidade pelos consumidores brasileiros, e à implantação do Plano Real, que propiciou aumento na renda real da população. A partir disso, o que se tem observado é que o consumo dessa bebida aumentou significativamente no Brasil. O consumidor brasileiro está ciente de que o produto possui tipos e qualidades diferentes, dada a introdução de novos produtos no mercado. Essa estratégia se tornou tão presente que, nos últimos anos, passou a despertar a atenção de empresas internacionais. O espaço do café nos supermercados foi ampliado para dar lugar a produtos de novos nichos. Foram abertas lojas de cafés que têm atraído 
o público jovem, a exemplo do que se observa nos mercados europeu e americano.

\section{Distribuição do recebimento e consumo familiar nas áreas analisadas e no total das áreas da $\mathrm{POF}$}

O número médio de pessoas por família, o número de famílias, o recebimento mensal per capita e o consumo de cafés nas 9 classes de recebimento mensal familiar, no ano de 2002/2003, nas regiões de Minas Gerais, Rio de Janeiro, São Paulo, Espírito Santo e no total das áreas da POF (Brasil), podem ser observados nas Tabelas 1 a 5.

Em Minas Gerais, observa-se que nas classes mais baixas havia maior número de famílias; o número de pessoas na família, de modo geral, variou pouco entre as classes de recebimento; e o número médio de pessoas na família, nesta região, foi de 3,66. O recebimento mensal familiar per capita, como era de esperar, foi maior nas classes de renda mais alta, e a diferença entre a classe de renda mais baixa e mais alta foi de $1650 \%$ (Tabela 1 ).

Com relação ao consumo de café torrado e moído na região de Minas Gerais, verifica-se que a classe que obteve o maior consumo per capita foi a de renda de $\mathrm{R} \$ 3000,00$ a $\mathrm{R} \$ 4000,00$, e a que obteve menor consumo per capita foi a mais baixa, cuja renda era até $\mathrm{R} \$ 400,00$. 
Tabela 1 - Número médio de pessoas por família, número de famílias, recebimento mensal per capita e consumo de café torrado e moído, em $\mathrm{Kg} /$ per capita, nas 9 classes de recebimento mensal familiar em Minas Gerais, 2002/2003

\begin{tabular}{ccccc}
\hline $\begin{array}{c}\text { Classes de } \\
\text { recebimento }\end{array}$ & $\begin{array}{c}\text { Número de } \\
\text { famílias }\end{array}$ & $\begin{array}{c}\text { Número médio } \\
\text { de pessoas por } \\
\text { família }\end{array}$ & $\begin{array}{c}\text { Recebimento } \\
\text { mensal per } \\
\text { capita }\end{array}$ & $\begin{array}{c}\text { Consumo de } \\
\text { café torrado e } \\
\text { moído }\end{array}$ \\
\hline Até 400 & $728.261,00$ & 2,85 & 270,55 & 3.32 \\
De 400 a 600 & $713.928,00$ & 3,15 & 490,63 & 4.02 \\
De 600 a 1000 & $1.127 .228,00$ & 3,64 & 780,24 & 4.86 \\
De 1000 a 1200 & $459.250,00$ & 3,65 & $1.088,37$ & 5.56 \\
De 1 200 a 1600 & $594.722,00$ & 3,85 & $1.377,59$ & 6.01 \\
De 1600 a 2000 & $375.155,00$ & 3,93 & $1.776,88$ & 5.47 \\
De 2000 a 3000 & $459.211,00$ & 3,92 & $2.389,66$ & 4.80 \\
De 3000 a 4000 & $259.583,00$ & 3,97 & $3.375,96$ & 6.89 \\
Mais de 4000 & $196.516,00$ & 3,95 & $4.734,03$ & 5.78 \\
Média & $545.983,78$ & 3,66 & $1.809,32$ & 5,19 \\
\hline
\end{tabular}

Fonte: POF 2002/2003, IBGE.

No Rio de Janeiro, a diferença entre o recebimento médio da classe mais alta e da mais baixa foi de mais de $1800 \%$, embora houvesse quase o dobro de famílias de classe mais baixa quando comparadas com as que recebiam mais (recebimento maior que $\mathrm{R} \$ 4000,00$ ). Se for comparado o número de famílias da classe que recebia de $\mathrm{R} \$ 600,00$ a $\mathrm{R} \$ 1000,00$ com o da classe de mais de $\mathrm{R} \$ 4000,00$, a diferença é ainda maior, mais de três vezes. O número médio de pessoas na família ficou em torno de 3,66 , em todas as classes de recebimento (Tabela 2). 
Tabela 2 - Número médio de pessoas por família, número de famílias, recebimento mensal per capita e consumo de café torrado e moído, em $\mathrm{Kg} /$ per capita, nas 9 classes de recebimento mensal familiar no Rio de Janeiro, 2002/2003

\begin{tabular}{ccccc}
\hline $\begin{array}{c}\text { Classes de } \\
\text { recebimento }\end{array}$ & $\begin{array}{c}\text { Número de } \\
\text { famílias }\end{array}$ & $\begin{array}{c}\text { Número médio } \\
\text { de pessoas por } \\
\text { família }\end{array}$ & $\begin{array}{c}\text { Recebimento } \\
\text { mensal per } \\
\text { capita }\end{array}$ & $\begin{array}{c}\text { Consumo de } \\
\text { café torrado e } \\
\text { moído }\end{array}$ \\
\hline Até 400 & 512.322 & 3,02 & 252 & 2,10 \\
De 400 a 600 & 548.598 & 3,08 & 487 & 4,03 \\
De 600 a 1000 & 933.682 & 3,08 & 764 & 3,15 \\
De 1000 a 1200 & 394.696 & 3,22 & 1.091 & 2,76 \\
De 1 200 a 1600 & 516.721 & 3,48 & 1.362 & 3,57 \\
De 1600 a 2000 & 326.008 & 3,47 & 1.734 & 4,23 \\
De 2000 a 3000 & 416.922 & 3,26 & 2.461 & 3,30 \\
De 3000 a 4000 & 248.046 & 3,32 & 3.374 & 5,82 \\
De 4000 & 298.845 & 3,40 & 4.928 & 6,74 \\
Média & 466.204 & 3,26 & 1.828 & 3,97 \\
\hline
\end{tabular}

Fonte: POF 2002/2003, IBGE.

Com relação ao consumo de café na região do Rio de Janeiro, observase que a classe mais alta consumia mais café torrado e moído e que, assim como em Minas Gerais, a classe mais baixa consumia menos. Isto pode indicar uma possibilidade de incremento no consumo desse tipo de café pelas classes de recebimento até $\mathrm{R} \$ 400,00$, dados os acréscimos em suas rendas.

Em São Paulo, observou-se que na classe de recebimento de $\mathrm{R} \$ 2000,00$ a R\$ 3000,00 havia maior número de pessoas por família, 3,75. Em contrapartida, nas famílias com renda até $\mathrm{R} \$ 600,00$ havia menor número de pessoas, 2,55. Com relação ao recebimento mensal per capita, houve aumento de mais de $1600 \%$ no recebimento médio da classe de recebimento mais baixa para a mais alta (Tabela 3 ). 
Tabela 3 - Número médio de pessoas por família, número de famílias, recebimento mensal per capita e consumo de café torrado e moído, em $\mathrm{Kg} /$ per capita, nas 9 classes de recebimento mensal familiar em São Paulo, 2002/2003

\begin{tabular}{ccccc}
\hline $\begin{array}{c}\text { Classes de } \\
\text { recebimento }\end{array}$ & $\begin{array}{c}\text { Número de } \\
\text { famílias }\end{array}$ & $\begin{array}{c}\text { Número médio de } \\
\text { pessoas por família }\end{array}$ & $\begin{array}{c}\text { Recebimento } \\
\text { mensal per } \\
\text { capita }\end{array}$ & $\begin{array}{c}\text { Consumo de café } \\
\text { torrado mó́do }\end{array}$ \\
\hline Até 400 & 602.468 & 2,55 & 279 & 4,26 \\
De 400 a 600 & 913.645 & 3,02 & 496 & 3,18 \\
De 600 a 1000 & 2.028 .510 & 3,37 & 776 & 3,72 \\
De 1000 a 1200 & 873.784 & 3,53 & 1.088 & 4,83 \\
De 1 200 a 1600 & 1.481 .957 & 3,40 & 1.368 & 4,23 \\
De 1600 a 2000 & 1.046 .605 & 3,33 & 1.770 & 5,57 \\
De 2000 a 3000 & 1.604 .273 & 3,75 & 2.420 & 4,99 \\
De 3000 a 4000 & 944.458 & 3,54 & 3.441 & 4,13 \\
Mais de 4000 & 891.619 & 3,73 & 4.779 & 3,82 \\
Média & 1.154 .147 & 3,36 & 1.824 & 4,30 \\
\hline
\end{tabular}

Fonte: POF 2002/2003, IBGE.

O maior consumo de café torrado e moído ocorrido em São Paulo, em 2002/2003, foi efetuado pela classe dos que recebiam de R $\$ 1600,00$ e $\mathrm{R} \$ 2000,00(5,57)$, enquanto a classe até $\mathrm{R} \$ 400,00$ teve consumo per capita de café próximo ao obtido pela média do consumo de todas as classes.

No Estado do Espírito Santo, a análise foi semelhante à dos outros estados, e o número de famílias nas classes de recebimento mais baixas foi, em geral, mais alto que nas outras classes de recebimento. $\mathrm{O}$ recebimento mensal per capita variou de $1600 \%$, entre a primeira e a última classe. Com relação ao consumo de café torrado e moído nesta região, pode-se dizer que os que recebiam até $\mathrm{R} \$ 400,00$ consumiam menos e os que recebiam de $\mathrm{R} \$ 3000,00$ a $\mathrm{R} \$ 4000,00$ tiveram maior consumo médio (Tabela 4). 
Tabela 4 - Número médio de pessoas por família, número de famílias, recebimento mensal per capita e consumo de café torrado e moído, em Kg/per capita nas 9 classes de recebimento mensal familiar no Espírito Santo, 2002/2003

\begin{tabular}{ccccc}
\hline $\begin{array}{c}\text { Classes de } \\
\text { recebimento }\end{array}$ & $\begin{array}{c}\text { Número de } \\
\text { famílias }\end{array}$ & $\begin{array}{c}\text { Número médio } \\
\text { de pessoas por } \\
\text { família }\end{array}$ & $\begin{array}{c}\text { Recebimento } \\
\text { mensal per } \\
\text { capita }\end{array}$ & $\begin{array}{c}\text { Consumo de } \\
\text { café torrado e } \\
\text { moído }\end{array}$ \\
\hline Até 400 & 136.095 & 2,96 & 278,89 & 1,88 \\
De 400 a 600 & 119.455 & 3,23 & 492,66 & 2,20 \\
De 600 a 1000 & 215.655 & 3,53 & 774,30 & 2,28 \\
De 1000 a 1200 & 71.881 & 3,60 & $1.082,00$ & 2,40 \\
De 1 200 a 1600 & 101.470 & 3,63 & $1.369,38$ & 2,48 \\
De 1600 a 2000 & 62.540 & 3,91 & $1.759,35$ & 1,73 \\
De 2000 a 3000 & 84.983 & 3,82 & $2.407,21$ & 3,71 \\
De 3000 a 4000 & 38.758 & 3,59 & $3.318,88$ & 4,32 \\
Mais de 4000 & 41.610 & 3,69 & $4.828,66$ & 4,07 \\
Média & 96.939 & 3,55 & 1.812 & 2,79 \\
\hline
\end{tabular}

Fonte: POF 2002/2003, IBGE.

A Tabela 5 apresenta a análise do número médio de pessoas por família e o recebimento mensal per capita, no total das áreas da POF (Brasil). Observa-se que, em média, a classe que recebia até $\mathrm{R} \$ 400,00$, a mais baixa, possuía menor número médio de pessoas por família. $\mathrm{O}$ recebimento per capita variou em torno de $1700 \%$, entre a classe que recebia até $R \$ 400,00$ e a que recebia mais de $R \$ 4000,00$. 
Tabela 5 - Número médio de pessoas por família, número de famílias, recebimento mensal per capita e consumo de café torrado e moído, em Kg/per capita, nas 9 classes de recebimento mensal familiar no total das áreas da POF - Brasil, 2002/ 2003

\begin{tabular}{ccccc}
\hline $\begin{array}{c}\text { Classes de } \\
\text { recebimento }\end{array}$ & $\begin{array}{c}\text { Número de } \\
\text { famílias }\end{array}$ & $\begin{array}{c}\text { Número médio } \\
\text { de pessoas por } \\
\text { família }\end{array}$ & $\begin{array}{c}\text { Recebimento } \\
\text { mensal per } \\
\text { capita }\end{array}$ & $\begin{array}{c}\text { Consumo de } \\
\text { café torrado e } \\
\text { moído }\end{array}$ \\
\hline Até 400 & $5.539 .767,00$ & 3,13 & 262,99 & 3,29 \\
De 400 a 600 & $5.243 .746,00$ & 3,39 & 490,90 & 3,73 \\
De 600 a 1000 & $8.381 .090,00$ & 3,57 & 772,91 & 3,77 \\
De 1000 a 1200 & $3.128 .224,00$ & 3,66 & $1.086,75$ & 4,28 \\
De 1 200 a 1600 & $4.571 .594,00$ & 3,65 & $1.366,09$ & 4,08 \\
De 1600 a 2000 & $3.108 .450,00$ & 3,65 & $1.766,54$ & 4,47 \\
De 2000 a 3000 & $4.297 .623,00$ & 3,76 & $2.412,04$ & 4,37 \\
De 3000 a 4000 & $2.309 .661,00$ & 3,69 & $3.412,78$ & 4,36 \\
Mais de 4000 & $2.161 .242,00$ & 3,72 & $4.812,27$ & 4,30 \\
Média & $4.304 .599,67$ & 3,58 & $1.820,36$ & 4,07 \\
\hline
\end{tabular}

Fonte: POF 2002/2003, IBGE.

O consumo de café torrado e moído, de modo similar às demais regiões estudadas, foi menor nas classes mais baixas e maior nas mais altas.

O comportamento do número médio de pessoas por família, do número de famílias, do recebimento mensal per capita e do consumo de café torrado e moído (per capita) foi semelhante nas regiões analisadas. $\mathrm{O}$ número de famílias foi maior na classe mais baixa e o número médio de pessoas por família, o recebimento médio e o consumo de café torrado e moído foram maiores nas classes que recebiam mais, quando comparadas com as que recebiam menos. 
Esses dados podem indicar que aumentos na renda das pessoas que se situavam na faixa de recebimento mais baixa provocavam aumentos no consumo de café torrado e moído no país.

\section{Modelo teórico}

O modelo teórico utilizado neste trabalho está fundamentado na teoria da demanda e refere-se às quantidades consumidas dos diferentes bens, a preços alternativos, em dado período de tempo (Varian, 1999), isto é, a curva de demanda informa a quantidade que os consumidores desejam comprar, à medida que muda o preço unitário. A curva de demanda possui inclinação negativa, já que, geralmente, os consumidores estão dispostos a comprar quantidades maiores, se o preço estiver mais baixo.

A demanda de uma mercadoria depende de seu preço, bem como da renda do consumidor e dos preços de outras mercadorias. Por exemplo, se o preço do café aumentar, a quantidade demandada cairá; no entanto, se a renda aumentar, a quantidade demandada também aumentará. Dessa maneira, freqüentemente, deseja-se saber o quanto a demanda irá aumentar ou diminuir, dadas as mudanças nas variáveis que a afetam. Para isso, utilizam-se elasticidades para medir o quanto uma variável pode ser afetada por outra.

Em economia, a relação que indica o quão sensível é a demanda de determinado bem, em relação a mudanças na sua renda, é expressa pela elasticidade-renda da demanda.

A elasticidade-renda da demanda é definida, então, pela mudança percentual na quantidade demandada de determinado bem, dividida pela mudança percentual na renda. Matematicamente, é expressa por

$E r=(\Delta \mathrm{Q} / \Delta \mathrm{R}) \mathrm{xR} / \mathrm{Q}$, 
em que $\Delta \mathrm{Q}$ é variação da quantidade demandada; $\Delta \mathrm{R}$, variação na renda do consumidor; $\mathrm{Q}$, quantidade inicialmente consumida; e R, renda nominal do consumidor antes da variação.

Quanto à classificação, tem-se que, se $E r>1$, o bem será considerado superior, ou seja, aumentos na renda do consumidor gerarão elevação mais que proporcional na quantidade demandada do bem; se $0<E r<1$, o bem será normal, o que significa que aumentos na renda resultarão em elevação menos que proporcional na quantidade demandada do bem; e se $E r<0$, o bem será inferior, e aumentos na renda indicarão decréscimo na quantidade demandada do bem.

O fato de um bem ser normal ou superior para um indivíduo e inferior para outro indica as preferências desses indivíduos e a classe de renda a que pertencem.

\section{Metodologia}

4.1. Modelo analítico: o método de determinação das elasticidades

A estimativa da elasticiadade-renda da despesa com café torrado e moído foi obtida pelo ajustamento de uma poligonal nos logaritmos dessas variáveis. Considerando uma poligonal com dois vértices (três segmentos), o modelo será:

$$
\ln y_{i}=\alpha+\beta \ln X_{i}+\sum_{h+1}^{2} \delta Z_{n i}\left(\ln X_{i}-\ln \theta_{n}\right)+u_{i}
$$

em que $\mathrm{X}_{\mathrm{i}}$ é recebimento per capita na i-ésima classe (com $\left.\mathrm{i}=1, \ldots, 10\right)$; $\mathrm{Y}$, consumo físico per capita da i-ésima classe; $\theta_{\mathrm{n}}$, nível de recebimento familiar per capita, correspondente ao h-ésimo vértice da poligonal com $\left(\theta_{1}<\theta_{2}\right)$; e $Z_{h i}$, variável binária, tal que $\mathrm{Z}_{\mathrm{hi}}$ é igual a 0 , para , $X_{i} \leq \theta_{h}$, $\mathrm{Z}_{\mathrm{hi}}$ é igual a 1 , para $X_{i}>{ }_{h}$. 
O modelo admite que os erros $u_{i}$ sejam independentes, com média zero e variância inversamente proporcional ao número de famílias na classe. Nesse caso, o ajustamento do modelo é feito pelo método dos mínimos quadrados ponderados, utilizando o número de famílias por classe como fator de ponderação (Hoffmann, 2000). Esta metodologia foi usada também por Tosta et a.l. (2003), Bacchi et al. (2001) e Martins et al. (2003).

Os três segmentos da poligonal correspondem a três grandes estratos delimitados por $\theta_{1}$ e $\theta_{2}$. No estrato I, $\operatorname{com} X_{1} \leq \theta_{l}$, a elasticidade será igual a $\beta$; no estrato II, $\operatorname{com} \theta_{1}<X \leq \theta_{2}$, a elasticidade-renda será igual a $\beta+\delta$; e no estrato III, $\operatorname{com} X>\theta_{2}$, a elasticidade será igual a $\beta+\delta_{1}+\delta_{2}$.

O limite entre os dois estratos de recebimento per capita $\left(\theta_{1}\right.$ ou $\left.\theta_{2}\right)$ é definido pelo limite entre duas classes de recebimento familiar da POF, dividido pela média geométrica dos tamanhos médios das famílias nessas duas classes.

A estimativa da elasticidade-renda média para toda população abrangida pela POF é a média ponderada das elasticidades em cada estrato, sendo fator de ponderação a participação de cada estrato no total de despesa com o produto analisado.

Existem 28 maneiras diferentes de agregar as 9 classes de recebimento familiar da POF em três grandes estratos. Os pacotes estatísticos programáveis trazem maneiras de desenvolver programas para executar as estimativas das elasticidades. O programa utilizado neste trabalho, para obtenção das estimativas das elasticidades, foi desenvolvido por $\operatorname{Lima}^{5}$ (2002).

O programa ajusta a poligonal para cada uma das 28 maneiras de fazer o agrupamento das 9 classes e ordena os resultados conforme valores decrescentes da soma de quadrados residual (ou valores decrescentes do coeficiente de determinação da regressão).

\footnotetext{
5 POLIGON - Programa desenvolvido por Lima (2002), a partir do software Eviews 4.0.
} 
O comportamento esperado para a elasticidade-renda da demanda de café moído e solúvel é que o consumo aumente, do primeiro para o segundo estrato, e decresça, do segundo para o terceiro estrato.

\subsection{Fonte de dados}

Os dados utilizados neste trabalho foram retirados da Pesquisa de Orçamento Familiar (POF), do ano de 2002/2003, realizada pelo Instituto Brasileiro de Geografia e Estatística (IBGE, 2004), e referem-se à despesa familiar per capita e ao recebimento familiar per capita. A escolha das POF, de 2002/2003, se deve à maior disponibilidade de informações, já que esta difere das POFs anteriores, por incluir informações sobre todo o território brasileiro, e não apenas sobre regiões metropolitanas, bem como informações detalhadas sobre as condições de vida, a partir do consumo, especialmente das famílias de menor rendimento, e engloba ainda as áreas rurais e as aquisições não-monetárias.

\section{Resultados e discussão}

Nas Tabelas 6 a 10 são apresentados os resultados da elasticidade-renda do consumo de café nas regiões de Minas Gerais, Rio de Janeiro, São Paulo, Espírito Santo e no total das áreas da POF (Brasil), no ano de 2002/2003.

Essas tabelas dão informações do esquema de agrupamento das 9 classes de recebimento familiar da $\mathrm{POF}$, o coeficiente de determinação $\left(\mathrm{R}^{2}\right)$ da equação de regressão ajustada, as elasticidades em cada um dos estratos e a elasticidade média, que foi escolhida com base nos três maiores coeficientes de determinação dentre os agrupamentos.

Nos resultados encontrados há muitos casos em que a elasticidade-renda não se comportou como previsto, já que apresentou valores negativos em vários estratos. Como justificativa, considera-se a afirmativa de 
Hoffmann (2000), de que não se deve confiar totalmente nas elasticidades estimadas para estratos individuais, pois, em muitos agrupamentos, um estrato é formado por apenas uma classe de recebimento, dando origem a uma estimativa de elasticidade imprecisa e que se refere a uma parcela restrita da população. Com base nisso, pode-se dizer que as estimativas da elasticidade média são mais confiáveis do que as da elasticidade em cada estrato.

Um esquema de agrupamento 6-1-3, por exemplo, significa que o primeiro estrato (I) inclui as seis primeiras classes de recebimento familiar da POF; o segundo estrato (II), a classe seguinte; e o terceiro estrato (III), as três últimas.

Para o Estado de Minas Gerais, observou-se, nos três agrupamentos, redução da elasticidade-renda do café torrado e moído, do primeiro para o segundo e deste para o terceiro, e comportamento distinto no estrato de maior coeficiente de determinação $\left(\mathrm{R}^{2}\right)$. A elasticidade foi de 0 a 1,0 que indica que este é um bem normal. Quanto à elasticidade média, observa-se que esta apresentou o mesmo resultado, ou seja, valores positivos e menores que um, sendo a elasticidade média menor para coeficientes de determinação menores.

Tabela 6 - Elasticidade-renda do consumo de café torrado e moído em 
No Rio de Janeiro, a elasticidade-renda reduziu, do primeiro para o segundo estrato, e aumentou, do segundo para o terceiro estrato, tanto no primeiro $(2,52)$ quanto no terceiro esquema de agrupamento (2-6-1). No segundo esquema de agrupamento, a elasticidade foi negativa, no primeiro e no segundo estrato, e variou de 0 a 1 , no terceiro estrato. A elasticidade média estimada foi positiva e menor que um, nos três esquemas de agrupamento em análise.

Tabela 7 - Elasticidade-renda do consumo de café torrado e moído no Rio de Janeiro, 2002/2003

\begin{tabular}{cccccc}
\hline \multirow{2}{*}{$\begin{array}{c}\text { Esquema de } \\
\text { agrupamento }\end{array}$} & \multirow{2}{*}{$\mathrm{R}^{2}$} & \multicolumn{3}{c}{ Elasticidades no estrato } & Elasticidade \\
\cline { 3 - 6 } & & $\mathrm{I}$ & $\mathrm{II}$ & $\mathrm{III}$ & média \\
\hline $2-5-2$ & 0,83521 & 0,78059 & 0,29097 & 0,48837 & 0,44449 \\
$1-6-2$ & 0,81381 & $-0,82525$ & $-0,02399$ & 0,40046 & 0,07821 \\
$2-6-1$ & 0,78730 & 0,86465 & 0,34071 & 0,49762 & 0,46030 \\
\hline
\end{tabular}

Fonte: Resultados da pesquisa.

No Estado de São Paulo, a elasticidade-renda da demanda do café torrado e moído reduziu-se, do primeiro para o segundo estrato e, novamente, do segundo para o terceiro, no primeiro esquema de agrupamento (1-6-2), que apresentou maior R2. Comportamento diferenciado foi observado nos demais esquemas de agrupamento, em que todas as elasticidades foram negativas, com exceção de um único estrato. A elasticidade média foi positiva e menor que um nos agrupamentos que apresentaram maior coeficiente de ajustamento, e negativa no que apresentou menor R2. 
Tabela 8 - Elasticidade-renda do consumo de café torrado e moído em São Paulo, 2002/2003

\begin{tabular}{|c|c|c|c|c|c|}
\hline \multirow{2}{*}{$\begin{array}{l}\text { Esquema de } \\
\text { agrupamento }\end{array}$} & \multirow[b]{2}{*}{$\mathrm{R}^{2}$} & \multicolumn{3}{|c|}{ Elasticidades no estrato } & \multirow{2}{*}{$\begin{array}{l}\text { Elasticidade } \\
\text { média }\end{array}$} \\
\hline & & I & II & III & \\
\hline $1-6-2$ & 0,93980 & 0,94791 & 0,30221 & 0,01648 & 0,31458 \\
\hline $3-4-2$ & 0,92324 & $-0,06879$ & 0,13379 & $-0,06646$ & 0,03431 \\
\hline $2-1-6$ & 0,90081 & $-0,67370$ & $-0,33198$ & $-0,06478$ & $-0,20742$ \\
\hline
\end{tabular}

Fonte: Resultados da pesquisa.

Os resultados encontrados para a elasticidade-renda do café torrado e moído, no Espírito Santo, indicam redução no consumo, do primeiro para o segundo estrato, e aumento, do segundo para o terceiro. No segundo estrato, a elasticidade-renda foi negativa, o que indica que, na classe de recebimento de $\mathrm{R} \$ 1600,00$ a $\mathrm{R} \$ 2000,00$, o café torrado e moído é um bem inferior.

A explicação para esse resultado pode ser obtida quando se analisa o esquema de agrupamento. O segundo estrato é composto por apenas uma classe de recebimento, o que acarreta elasticidade-renda negativa no estrato II $(-0,12347)$. Nesse caso, é mais confiável analisar os resultados pela elasticidade média; dado que esta se situa entre 0 e 1 , pode-se definir o café torrado e moído como um bem normal. Os demais esquemas de agrupamento também apresentaram elasticidade-renda positiva e menor que um. 
Tabela 9 - Elasticidade-renda do consumo de café torrado e moído no Espírito Santo, 2002/2003

\begin{tabular}{|c|c|c|c|c|c|}
\hline \multirow{2}{*}{$\begin{array}{l}\text { Esquema de } \\
\text { agrupamento }\end{array}$} & \multirow[b]{2}{*}{$\mathrm{R}^{2}$} & \multicolumn{3}{|c|}{ Elasticidades no estrato } & \multirow{2}{*}{$\begin{array}{l}\text { Elasticidade } \\
\text { média }\end{array}$} \\
\hline & & I & II & III & \\
\hline $5-1-3$ & 0,97241 & 0,16511 & $-0,12347$ & 0,36764 & 0,24295 \\
\hline $1-5-3$ & 0,86818 & $-0,37333$ & $-0,05618$ & 0,29279 & 0,08847 \\
\hline $4-2-3$ & 0,85640 & 0,16207 & 0,04292 & 0,36189 & 0,23851 \\
\hline
\end{tabular}

Fonte: Resultados da pesquisa.

Para o Brasil, a elasticidade apresentou-se negativa, no primeiro e segundo estrato, e de 0 a 1 , no terceiro esquema de agrupamento maior $\mathrm{R}^{2}$. No segundo e terceiro esquemas de agrupamento, ela reduziu-se, do primeiro para o segundo e do segundo para o terceiro, de 0 para 1. A elasticidaderenda média foi positiva e menor que um, em todos os agrupamentos em análise. Tal coeficiente indica que o café torrado e moído é um bem normal, ou seja, que aumentos na renda contribuíram para aumentos menos que proporcionais no consumo desse bem.

Tabela 10 - Elasticidade-renda do consumo de café torrado e moído no Brasil, 2002/2003

\begin{tabular}{ccccccc}
\hline \multirow{2}{*}{$\begin{array}{c}\text { Esquema de } \\
\text { agrupamento }\end{array}$} & $\mathrm{R}^{2}$ & \multicolumn{4}{c}{ Elasticidades no estrato } & Elasticidade \\
\cline { 3 - 6 } & & $\mathrm{I}$ & $\mathrm{II}$ & $\mathrm{III}$ & média \\
\hline $1-2-6$ & 0,98997 & $-0,26169$ & $-0,03825$ & 0,04833 & 0,00279 \\
$2-5-2$ & 0,98734 & 0,18690 & 0,14701 & 0,07382 & 0,13736 \\
$6-1-2$ & 0,98733 & 0,14542 & 0,11627 & 0,07199 & 0,12459 \\
\hline
\end{tabular}

Fonte: Resultados da pesquisa. 


\section{Conclusões}

Os coeficientes estimados das elasticidades-renda médias de café torrado e moído apresentaram valores positivos e menores que a unidade, o que indica que o café é um bem normal.

As elasticidades-renda médias de café torrado e moído, referentes aos agrupamentos de maior coeficiente de determinação $\left(\mathrm{R}^{2}\right)$, foram maiores nos estados da região Sudeste (Minas Gerais, 0,28780; Rio de Janeiro, 0,44449; São Paulo, 0,31458; e Espírito Santo, 0,24295), comparativamente à obtida para o Brasil $(0,00279)$.

Conclui-se que os consumidores de café na região Sudeste são mais sensíveis à mudança em suas rendas, quando comparados com os do Brasil.

\section{Referências bibliográficas}

Anuário Estatístico do Café. Coffee Business, Rio de Janeiro - RJ, 2002/2003, 101 p.

Associação Brasileira da Indústria de Café - ABIC - Estatísticas. Disponível em $<$ http//www.abic.com.br $>$. Acesso em agosto de 2005.

BACCHI, M. R. P., SPOLADOR, H. F. S. Elasticidade-renda do consumo físico de frango nas regiões metropolitanas do Brasil. In: CONGRESSO BRASILEIRO DE ECONOMIA E SOCIOLOGIA RURAL, 2001, Recife, Anais... Brasília: SOBER, 10 p., 2001.CD ROM.

COSTA, S. L. Demanda Interna de Café no Brasil: Novos Condicionantes e Perspectivas. Viçosa: UFV, 2003. 67 p. Dissertação (Mestrado em Economia Rural) - Universidade Federal de Viçosa, 2003. 
FEDERAÇÃO DA AGRICULTURA DO ESTADO DE MINAS GERAIS - FAEMG. Nota Técnica. Disponível em $<$ http// www.faemg.org.Br>. Acesso em 2003.

Fundação Instituto Brasileiro de Geografia e Estatística - IBGE Pesquisa de Orçamentos Familiares 2002-2003. Rio de janeiro, 2004. CD ROM.

GOMES, M. F. M.et al. A Cadeia Agroindustrial do Café. In: Minas Gerais do Século XXI. Banco de Desenvolvimento de Minas Gerais (BDMG). Belo Horizonte: Rona Editora, volume IV, Transformando o desenvolvimento na agropecuária, 2002, p. 51 a 59.

HEMERLY, F. X. Cadeia produtiva do café no estado de São Paulo: possibilidades de melhoria de sua competitividade no segmento agrícola. 239 f. Tese (Doutorado em Engenharia Agrícola) Universidade Estadual de Campinas, Campinas, SP, 2000.

HOFFMANN, R. Elasticidades-renda das despesas e do consumo físico de alimentos no Brasil metropolitano em 1995-96. Agricultura em São Paulo. São Paulo, SP. IEA, v. 47, nº 1, 2000.

Instituto Brasileiro de Geografia e Estatística - IBGE - Pesquisa de Orçamento Familiar (POF) 2002/2003. Disponível em $<\mathrm{http} / /$ www.ibge.gov.br> Acesso em julho de 2005 .

MARTINS, A. G.; PIMENTEL, E. R.; LIMA, J. E.; ROSADO, P. L. Análise do consumo de carne bovina nas regiões metropolitanas do Brasil. In: XLI Congresso Brasileiro de Economia e Sociologia Rural, 2003, Juiz de Fora - MG. CD ROM do XLI Congresso Brasileiro de Economia e Sociologia Rural. SOBER, 2003, p. 1-12.

TOSTA, M. C. T.; CAMPOS, S. K.; FERREIRA, S. Elasticidade-renda do consumo de leite e seus derivados no Brasil em 1996. .In: XLI Congresso Brasileiro de Economia e Sociologia Rural, 2003, Juiz de Fora - MG. CD ROM do XLI Congresso Brasileiro de Economia e Sociologia Rural. SOBER, 2003, p. 1-8. 


\title{
VARIAN, H. R. Microeconomia - Princípios Básicos. Tradução da $2^{\circ}$ edição americana. Rio de Janeiro: Editora Campus Ltda, 1999. 732 p.
}

\begin{abstract}
This paper aimed to assess the changes in the consumption quantity of roasted and ground coffee in response to changes in the consumers' income, in the Southeast Region of Brazil, specifically in the states of Minas Gerais, São Paulo and Rio de Janeiro, and in all areas of the covered by the POF (Brazil). For that, the income elasticity of the consumption of those types of coffees was estimated by using an econometric model that fitted a three-segment polygon to show as the per capita physical consumption of those types of coffee varies as the per capita family monthly income changes. The data were gathered from the Family Budget Survey for the years of 2002/2003, published by the IBGE. The estimated income elasticity for roasted and ground coffee was greater than zero and smaller than one, suggesting that this product is considered a normal good in the analyzed regions, i.e., a variation in the consumer's income will lead to a less than proportional variation in the coffee consumption.
\end{abstract}

Key-words: Income elasticity, coffee consumption, Southeast Region. 